\title{
IMPLEMENTATION OF DIGITAL LITERACY IN SOCIAL SCIENCES EDUCATION ELEMENTARY SCHOOL WITH WAYANG MEDIA FOR STKIP BINA INSAN MANDIRI PGSD STUDENTS
}

\author{
Zuni Eka Tiyas Rifayanti, Evi Rizki Salamah \\ STKIP Bina Insan Mandiri \\ zunieka@stkipbim.ac.id
}

\begin{tabular}{l} 
Article History \\
\hline accepted 30/09/2018 \\
approved 12/10/2018 \\
published 30/10/2018
\end{tabular}

Keywords

Digital literacy, information, technology

\begin{abstract}
Digital literacy referred to in the study here is the use of information technology as an alternative learning resource to support student literature in elementary school social studies courses and the use of puppet media in teaching puppet material Indonesian independence figures. The rapid development of information technology requires us to be able to use it for educational purposes. If the world of education can make good use of information technology, it is not impossible, the development of education will be better. One of the uses of information technology is the use of Digital Literacy in the learning process. This type of research is descriptive research with qualitative and quantitative approaches. From the results of the research that has been done and by looking at the discussion above, it can be seen that there is an increase and success in the application of a digital literacy culture in the scope of the STKIP Bina Insan Mandiri PGSD Study Program. The results of this study indicate that students who are able to carry out digital literacy and are accustomed to literacy have been proven from the test results and observations obtained by researchers.
\end{abstract}

Social, Humanities, and Education Studies (SHEs): Conference Series https://jurnal.uns.ac.id/shes
p-ISSN 2620-9284 e-ISSN 2620-9292 


\section{PENDAHULUAN}

Literasi digital pada lingkup prodi PGSD STKIP Bina Insan Mandiri harus dikembangkan sebagai mekanisme pembelajaran terintegrasi dalam kurikulum atau setidaknya terkoneksi dengan sistem belajar mengajar. Mahasiswa perlu ditingkatkan keterampilannya, sebagai calon guru yang sedang menempuh pendidikan tinggi di sekolah tinggi ilmu keguaruan dan pendidikan maka perlu ditingkatkan pengetahuan dan kreativitasnya dalam proses pengajaran literasi digital, dan dosen perlu memfasilitasi mahasiswa dalam mengembangkan budaya literasi digital.

Fasilitas penunjang yang sudah disediakan oleh kampus dalam pelaksanaan literasi digital pada mahasiswa PGSD khususnya pada implementasi literasi digital matakuliah Pendidikan IPS SD. Mahasiswa diberikan pembelajaran tentang pemanfaatan media digital dalam pembelajaran, serta mahasiswa didorong untuk menggunakan teknologi informasi dan komunikasi secara cerdas dan bijaksana. Penerapan di sini juga ditekankan pada keteladanan yang diberikan oleh dosen terkait dengan penerapan literasi digital.

Bawden (2001) menawarkan pemahaman baru mengenai literasi digital yang berakar pada literasi komputer dan literasi informasi. Literasi komputer berkembang pada dekade 1980-an, ketika komputer mikro semakin luas dipergunakan, tidak saja di lingkungan bisnis, tetapi juga di masyarakat. Namun, literasi informasi baru menyebar luas pada dekade 1990-an manakala informasi semakin mudah disusun, diakses, disebarluaskan melalui teknologi informasi berjejaring. Dengan demikian, mengacu pada pendapat Bawden, literasi digital lebih banyak dikaitkan dengan keterampilan teknis mengakses, merangkai, memahami, dan menyebarluaskan informasi.Menurut Paul Gilster dalam bukunya yang berjudul Digital Literacy (1997), literasi digital diartikan sebagai kemampuan untuk memahami dan menggunakan informasi dalam berbagai bentuk dari berbagai sumber yang sangat luas yang diakses melalui piranti komputer.

Sementara itu, Douglas A.J. Belshaw dalam tesisnya What is 'Digital Literacy"? (2011) mengatakan bahwa ada delapan elemen esensial untuk mengembangkan literasi digital, yaitu sebagai berikut. 1. Kultural, yaitu pemahaman ragam konteks pengguna dunia digital; 2. Kognitif, yaitu daya pikir dalam menilai konten; 3. Konstruktif, yaitu reka cipta sesuatu yang ahli dan aktual; 4. Komunikatif, yaitu memahami kinerja jejaring dan komunikasi didunia digital; 5. Kepercayaan diri yang bertanggung jawab; 6 . Kreatif, melakukan hal baru dengan cara baru; 7. Kritis dalam menyikapi konten; dan 8. Bertanggung jawab secara sosial.

Beberapa hal yang bisa dilakukan dalam peningkatan jumlah dan ragam sumber belajar bermutu terkait literasi digital di lingkungan Prodi PGSD STKIP Bina Insan Mandiri adalah sebagai berikut.

1. Penambahan Bahan Bacaan Literasi Digital di Perpustakaan

Perpustakaan menjadi salah satu fasilitas bahan bacaan literasi dalam berbagai bentuk sumber belajar yang perlu ditingkatkan demi kebaharuan koleksi daftar buku yang tersedia. Dalam rangka penunjang terkait literasi digital khususnya pada matakuliah pendidikan IPS SD maka perpustakaan menyediakan bahan bacaan bertemakan digital, menyediakan bahan bacaan dalam bentuk salinan lunak, atau penyediaan alat peraga sebagai sumber belajar terkait dengan literasi digital yang dapat di akses luas oleh mahasiswa melalui jaringan WAN.

2. Penyediaan Situs-Situs Edukatif sebagai Sumber Belajar

Situs edukatif dapat digunakan oleh seluruh mahasiswa PGSD STKIP Bina Insan Mandiri. Dengan cara mahasiswa dapat menggunakan situs ruangguru.com atau belajar.indonesiamengajar.org atau situs lain untuk mengembangkan pengetahuan diri terkait dengan pembelajaran. kemdikbud.go.id atau sekolahaman.kemdikbud.go.id sebagai sumber belajar yang dapat di ambil sebagai mahasiswa calon guru sekolah dasar. 


\section{Penggunaan Aplikasi-Aplikasi Edukatif sebagai Sumber Belajar}

Aplikasi-aplikasi edukatif yang bisa digunakan oleh mahasiswa yang dapat dikaitkan aplikasi-aplikasi tersebut dalam pembelajaran. Pada mata kuliah pendidikan IPS SD maka mahasiswa dituntut untuk dapat membuat suatu media pembelajaran berbasis ICT.

Literasi digital yang dimaksud dalam kajian disini adalah pemanfaatan teknologi informasi sebagai salah satu alternative sumber belajar untuk menunjang literatur mahasiswa dalam matakuliah pendidikan IPS SD. Kami sadar bahwa perkembangan teknologi informasi sangat pesat. Jika dibandingkan dengan perkembangan pendidikan, dengan adanya kemajuan teknologi informasi yang begitu pesat. Perkembangan teknologi informasi ini menuntut kita agar mampu memanfaatkannya untuk kepentingan pendidikan. Jika dunia pendidikan dapat memanfaatkan teknologi informasi dengan baik, maka bukan tidak mungkin, perkembangan pendidikan akan lebih baik. Salah satu pemanfaatan teknologi informasi adalah penggunaan Literasi Digital dalam proses pembelajaran.

Literasi digital dalam pembelajaran dapat dibuat dengan mengembangkan Sumber-sumber belajar berbasis Teknologi Informasi. Sumber belajar yang dijadikan dalam matakuliah pendidikan IPS SD pada prodi PGSD STKIP Bina Insan Mandiri ini sebagai salah satu bentuk literasi digital setidaknya ada dua macam, yakni yang bersifat offline maupun online. Sumber belajara yang bersifat offline multimedia pembelajaran interaktif. Adapun untuk sumber belajar digital berbasis online di antaranya adalah blog pembelajaran, Sistem informasi menejemen (SIM) dan website. Dalam pembelajaran di kelas, dalam hal ini dosen diminta tidak hanya menggunakan media dan metode pembelajaran konvensional. Dosen diminta untuk mengembangkan media pembelajaran yang interaktif. Media Pembelajaran Interaktif ini dapat dibuat oleh dosen dengan menggunakan software-software presentasi seperti Power Point, E-book,Flash, Lectora dan sebagainya. Sofware yang banyak digunakan oleh dosen adalah Power Point dan studi pustaka online dengan alamat web yang dapat diakses bebas oleh mahasiswa. Tidak jarang dosen seringkali menggunakan power point sebagai gagasan utama dalam penyajian informasi ketika pelaksanaan proses pembelajaran, dan agar menjadi lebih interaktif, Power Point dapat dimaksimalkan dengan animasi, video, audio, maupun visual basic yang tidak mengurangi dari isi materi yang akan disajikan.

Blog Pembelajaran dapat dibangun oleh dosen dengan mahasiswa sesuai dengan bidang ajar yang diampunya. Blog pembelajaran sangat baik untuk dijadikan sebagai proses pembelajaran digital. Berbeda dengan MPI, Blog dosen dapat digunakan sebagai sumber belajar di mana pun dan kapan pun. Konten blog pembelajaran haruslah berisi tentang bahan-bahan pembelajaran seperti perangkat pembelajaran, materi, latihan maupun evaluasi pembelajaran.Sumber literasi digital yang ketiga adalah website. Salah satu fungsi Website institusi adalah sebagai media komunikasi antara institusi dengan pihak luar institusi. Website insitusi memberikan informasi tentang institusi, seperti kurikulum, kalender pendidikan, kegiatan kemahasiswaan dll. Selain itu, Sistem Informasi Menejemen (SIM) yang tersedia di STKIP Bina Insan Mandiri dapat dijadikan sebagai sumber literasi digital yang berisi tentang bahan dan program pembelajaran untuk matakuliah Pendidikan IPS SD yang diajarkan oleh dosen tersebut.

Membangun Budaya Literasi Digital dalam hal ini diibaratkan Seperti layaknya membangun budaya literasi di sekolah yang diungkapkan oleh Johan Wahyudi, setidaknya ada tiga hal yang dapat digunakan untuk membangun budaya literasi digital. Di antaranya adalah pembelajaran interaktif, penugasan guru, pemberian reward, pengubahan perilaku digital dalam kegiatan sehari hari hal ini di implementasikan dalam literasi digital.

Pembelajaran interaktif dapat dilakukan melalui multimedia interaktif maupun 
blog dosen pengampu matakuliah. Jaringan Internet di Kawasan STKIP Bina Insan Mandiri dimanfaatkan sebaik-baiknya untuk proses pembelajaran online. Budaya Literasi digital dibangun agar mahasiswa terbiasa dengan membaca konten-konten pembelajaran yang tersedia secara offline maupun online dengan diharapkan membuka wawasan mahasiswa secara luas dan memudahkan dalam pencarian daftar literatur penunjang materi ajar perkuliahan. .

Penugasan matakuliah seperti TMT (Tugas Mandiri Terstruktur) dan TMTT (Tugas Mandiri Tidak Terstruktur) dapat dilakukan melalui pemanfaatan teknologi informasi. Salah satunya adalah penggunaan e-mail dan fasilitas Upload File di blog pembelajaran dan system informasi menejemen (SIM) STKIP Bina Insan Mandiri. Tugas yang dibuat oleh mahasiswa dengan diketik, tidak perlu dicetak. Namun bisa dikirim melalui e-mail guru. Juga dapat dikirim melalui Upload File di blog. Aplikasi HTML Form memungkinkan pengguna untuk menyediakan fasilitas mengirim File melalui blog tanpa menggunakan e-mail.

Berdasarkan latar belakang di atas, maka rumusan masalah yang dikemukakan dalam penelitian ini adalah :

1. Bagaimana aktivitas mahasiswa selama penerapan budaya literasi dalam kajian matakuliah pendidikan IPS SD?

2. Bagaimana hasil belajar mahasiswa setelah penerapan budaya literasi dalam kajian matakuliah pendidikan IPS SD?

\section{Jenis penelitian}

\section{METODE}

Jenis penelitian ini adalah penelitian deskriptif berpendekatan kualitatif dan kuantitatif. Deskriptif kualitatif dilaksanakan karena prosedur penelitian yang menghasilkan data deskriptif berupa ucapan atau tulisan dan perilaku orang-orang yang diamati. Sedangkan deskriptif kuantitatif dilaksanakan untuk mengolah data yang diperoleh dari hasil tes dalam pembelajaran pendidikan IPS pada materi kebudayaan yang diberikan kepada mahasiswa.

\section{Instrumen Penelitian}

Instrumen yang digunaan dalam penelitian ini adalah sebagai berikut :

1. Lembar observasi atau lembar pengamatan digunakan untuk mengetahui kemampuan Mahasiswa dalam melaksanakan proses pembelajaran berlangsung.

2. Lembar soal Tes hasil belajar yang diberikan disetiap akhir materi, berupa tes berbentuk pilihan ganda yang dikembangkan oleh peneliti berdasarkan tujuan pembelajaran yang berupa CAI.

\section{Teknik Pengumpulan Data}

Metode pengumpulan data yang digunakan oleh peneliti untuk memperoleh

1. Observasi

data-data yang dibutuhkan dalam penelitian adalah metode observasi dan tes.

Menurut Arikunto ( 2002 : 133) observasi sebagai aktivitas yang sempit, yakni memperhatikan sesuatu dengan menggunakan mata. Di dalam pengertian psikologik, observasi atau yang disebut juga dengan pengamatan, merupakan kegiatan pemusatan perhatian terhadap suatu obyek dengan menggunakan seluruh alat indra. Di dalam artian penelitian observasi dapat dilakukan dengan tes, kuesioner, rekaman gambar, dan rekaman suara.

Observasi dapat dilakukan dengan dua cara, yang kemudian digunakan untuk menyebut jenis observasi, yaitu :

1. Observasi non-sistematis, yang dilakukan oleh pengamat dengan tidak menggunakan intrumen pengamatan.

2. Observasi sistematis, yang dilakukan oleh pengamat dengan menggunakan intrumen pengamatan. 
Pedoman observasi berisi sebuah daftar jenis kegiatan yang mungkin timbul dan akan diamati. Dalam proses observasi, pengamat tinggal memberikan tanda atau tally pada kolom tempat peristiwa muncul.

Observasi merupakan tindakan pengambilan data melalui pengamatan terhadap halhal yang terjadi selama pelaksanaan proses pembelajaran. Perilaku yang diamati adalah aktivitas guru, aktivitas siswa maupun dalam kegiatan pembelajaran berdasarkan indikator kegiatan pembelajaran yang telah dipersiapkan oleh guru. Jadi observasi dalam penelitian ini dilakukan dalam bentuk skala penilaian selama proses pembelajaran dari kegiatan awal sampai kegiatan akhir.

2. Tes

Tes adalah serentetan pertanyaan atau latihan atau alat lain yang digunakan untuk mengukur keterampilan, pengetahuan, intelegensi, kemampuan antara bakat yang dimiliki oleh individu atau kelompok (Arikunto, 2002:127). Secara garis besar bentuk tes ada dua macam yaitu:

\section{a. Bentuk objektif}

Tes objektif yaitu tes yang jawabannya dapat diberi sekor nilai secara lugas (seadanya). Macam dari tes ragam objektif ini.

1) Tes benar-salah

Tes ini berbentuk pernyataan yang pilihan jawabannya hanya ada dua macam yaitu "B" jika pernyataan tersebut benar dan "S" jika salah.

2) Tes pilihan berganda

Tes ini berbentuk pilihan berganda biasanya berupa pernyataan yang dapat dijawab dengan memilih salah satu dari empat atau lima alternatif jawaban yang dilakukan dengan penyilangan.

3) Tes mencocokan (menjodohkan)

Tes ini berbentuk pencarian pasangan dari susunan dalam dua daftar yang masingmasing memuat kata,istilah, atau kalimat yang diletakan bersebelahan

4) Tes Isian

Tes ini berbentuk pengisian pada bagian tertentu (istilah atau nama tertentu) dalam cerita atau karangan pendek yang pada bagian tertentu (istilah atau nama tertentu) tersebut dikosongkan atau menemukan istilah atau nama tertentu yang dikosongkan dalam suatu cerita atau karangan pendek.

\section{b. Bentuk subjektif}

Tes subjektif yaitu tes yang jawabannya tidak ternilai dengan sekor atau angka yang pasti. Hal ini terjadi karena banyaknya ragam gaya jawaban yang diserikan oleh para siswa.Instrumen tes ini dalam bentuk essay examination, yakni soal ujian yang mengharuskan siswa menjawab setiap pertayaan dengan cara menguraikan atau dalam bentuk karangan bebas. Keunggulan bentuk tes ini adalah:

1) Tidak hanya mampu mengungkapkan hasil jawaban siswa,tetapi juga cara atau jalan yang ditempuh untuk memperoleh jawaban itu.

2) Dapat mendorong siswa untuk berfikir kreatif, kritis, bebas-mandiri tanpa melupakan tanggung jawab.

Dalam penelitian ini, peneliti menggunakan tes hasil belajar untuk mengukur pencapaian atau untuk mengetahui hasil belajar mahasiswa setelah menerapkan literasi digital matakuliah pendidikan IPS SD pada mahasiswa PGSD STKIP Bina Insan Mandiri . Peneliti menggunakan instrument berupa seperangkat soal-soal tes berupa soal objektif.

\section{b) Teknis Analisis Data}

Data kualitatif dari hasil pengamatan (observasi) dengan menggunakan lembar pengamatan yang dilakukan pada saat pembelajaran berlangsung dianalisis secara kualitatif. 
Keberhasilan Aktifitas Peneliti $=\frac{\sum \text { indikator kegiatan yang muncul }}{\sum \text { seluruh indikator }} x 100 \%$

Kemudian dikelompokkan berdasarkan pengkategorian kriteria kelulusan dengan batas-batas nilai kelulusan sebagai berikut :

$\begin{array}{ll}\text { Rentang Skor } & \text { Nilai } \\ 80 \% \text { s.d. } 100 \% & \text { A } \\ 70 \% \text { s.d. } 79 \% & \text { B } \\ 60 \% \text { s.d } 69 \% & \text { C } \\ 45 \% \text { s.d } 59 \% & \text { D } \\ \leq 44 \% & \text { E }\end{array}$

Sedangkan data kuantitatif yang berupa hasil belajar mahasiswa, dari jumlah skor yang diperoleh dari kegiatan pengumpulan data selanjutnya dia-nalisis untuk menentukan nilai hasil belajar yang diperoleh dengan mengu-bahnya yang menggunakan rumus sebagai berikut:

$\mathrm{P}=\frac{f}{N} X 100 \%$

Keterangan :

$\mathrm{P}=$ Prosentase

$\mathrm{F}=$ Jumlah skor yang diperoleh

$\mathrm{N}$ = Jumlah skor maksimal semua komponen yang diambil.

(Winarsunu, 2009 : 20)

Selanjutnya dilakukan analisis statistik deskriptif, bertujuan untuk mendeskripsikan hasil belajar matakuliah Pendidikan IPS yang dioperoleh mahasiswa. Hasil belajar kemudian dilakukan uji validitas dengan cara validitas external menggunakan rumus korelasi product moment sebagai berikut :

$$
R x y=\frac{\sum x y}{\sqrt{\left(\sum ( x ^ { 2 } ) \left(\sum\left(y^{2}\right)\right.\right.}}
$$

Keterangan :

$$
\begin{array}{lll}
R x y & =\text { deviasi } \\
X & =\text { hasil tes } X & \\
Y & =\text { hasil tes } Y \quad \text { Pearson (dalam Tulus Winarsunu:2009) }
\end{array}
$$

Tahap akhir penelitian adalah analisis data. Data yang telah diperoleh dianalisis menggunakan dua cara analisis.

1. Analisis isi, dilakukan pada subjek uji coba mahasiswa dan ahli bidang studi berwujud data kualitatif yang berupa masukan, tangggapan dan sarana perbaikan yang nantinya digunakan sebagai bahan revisi produk. Data dikumpulkan dalam bentuk angket.

2. Analisis deskriptif prosentase, berupa data kuantitatif yang diperoleh dari hasil isi yang dideskripsikan dengan teknik prosentase.

Rumus yang digunakan:

$$
\mathrm{P}=\frac{f}{N} \times 100
$$

Keterangan:

$\mathrm{P}=$ Prosestase nilai yang diperoleh 
$f=$ Frekuensi jawaban tiap alternatif

$\mathrm{N}=$ Nilai tertinggi yang semestinya diperoleh

Untuk memberikan makna terhadap angka prosentase digunakan ketetapan:

$\begin{array}{ll}76 \%-100 \% & =\text { Baik } \\ 56 \%-75 \% & =\text { Cukup } \\ 40 \%-55 \% & =\text { Kurang baik } \\ 0 \%-40 \% & =\text { Tidak baik }\end{array}$

(Suharsimi, Arikunto, 2009: 246)

HASIL DAN PEMBAHASAN

Dalam bab ini, penulis akan menguraikan tentang hasil-hasil penelitian dengan menggunakan teknik pengumpulan data. Teknik pengumpulan data yang dimaksud adalah tes dan observasi dalam penelitian ini, teknik pengumpulan data berupa tes yang dilakukan dengan praktik menggunakan CAT (computer Assisted Test) sebagai bentuk dari penerapan literasi digital.

\section{Hasil Tes}

Tabel 1. Data Hasil Tes ujian CAT (computer Assisted Test) mahasiswa PGSD

STKIP Bina Insan Mandiri dalam kajian matakuliah pendidikan IPS SD sebagai bentuk penerapan literasi digital

\begin{tabular}{|c|c|c|c|c|c|}
\hline & & & Kemampuan CAT d & alam tes & \\
\hline No & Nama & $L / P$ & $\begin{array}{l}\text { Sebelum literasi } \\
\text { digital }\end{array}$ & $\begin{array}{l}\text { Sesudah } \\
\text { digital }\end{array}$ & literasi \\
\hline 1 & Nadela Oktaviani & $\mathrm{P}$ & 50 & 80 & \\
\hline 2 & Rizky Catur Junaedi & $\mathrm{L}$ & 60 & 80 & \\
\hline 3 & Yopi Armanda & $\mathrm{L}$ & 35 & 67 & \\
\hline 4 & Yuliana Puspita Dewi & $\mathrm{P}$ & 47 & 67 & \\
\hline 5 & Andre Prasetyo & $\mathrm{L}$ & 62 & 85 & \\
\hline 6 & Bagus Setiawan & $\mathrm{L}$ & 78 & 84 & \\
\hline 7 & Bagus Septianto & $\mathrm{L}$ & 67 & 72 & \\
\hline 8 & Diani Tri Haswari & $\mathrm{P}$ & 95 & 77 & \\
\hline 9 & Dhea Catur S. & $\mathrm{P}$ & 80 & 82 & \\
\hline 10 & Ellian Affandi & $\mathrm{L}$ & 74 & 80 & \\
\hline 11 & Anang Ibnu Nursaleh & $\mathrm{L}$ & 60 & 77 & \\
\hline 12 & Haris Rachmat Fadillah & $\mathrm{L}$ & 75 & 85 & \\
\hline 13 & Januari & $\mathrm{L}$ & 75 & 90 & \\
\hline 14 & May Randi & $\mathrm{L}$ & 57 & 89 & \\
\hline 15 & Muhammad Erlangga & $\mathrm{L}$ & 45 & 85 & \\
\hline 16 & Mireya Firanda & $\mathrm{P}$ & 42 & 77 & \\
\hline 17 & Nila Dwi Irani & $P$ & 39 & 77 & \\
\hline 18 & Nadia Ayu Pitaloka & $P$ & 57 & 75 & \\
\hline 19 & Novia Permata Sari & $\mathrm{P}$ & 42 & 85 & \\
\hline 20 & Rizky Boy & $\mathrm{L}$ & 70 & 95 & \\
\hline 21 & Riska Fitrianingsih & $\mathrm{P}$ & 65 & 85 & \\
\hline 22 & Shogibatul Ummayah & $\mathrm{P}$ & 41 & 50 & \\
\hline 23 & Wahyu Adi Pratama S. & $\mathrm{L}$ & 70 & 65 & \\
\hline 24 & Rizal Feri Ardiansah & $\mathrm{L}$ & 24 & 55 & \\
\hline 25 & Firda Adila Dewi & $\mathrm{P}$ & 95 & 100 & \\
\hline 26 & Moh. Alfa Rizky & $\mathrm{L}$ & 47 & 47 & \\
\hline 27 & Nita Wijaya & $\mathrm{P}$ & 47 & 82 & \\
\hline Nila & Rata-rata & & 54.78 & 72.81 & \\
\hline
\end{tabular}


Dari tabel diatas, untuk mengetahui tingkat keberhasilan siswa dalam kegiatan CAT (computer Assisted Test) sebagai bentuk dari penerapan literasi digital dipergunakan prosentase berikut ini :

$$
\begin{aligned}
& P=\frac{n}{N} x 100 \% \\
& \text { Keterangan : } \\
& \mathrm{P} \quad \text { : Persentase yang diberi } \\
& \mathrm{n} \quad \text { : Jumlah nilai yang diperoleh siswa } \\
& \mathrm{N} \quad \text { : Jumlah seluruh siswa }
\end{aligned}
$$

\section{Hasil Observasi}

Tabel 2. Data Hasil Observasi mahasiswa PGSD STKIP Bina Insan Mandiri dalam kajian matakuliah pendidikan IPS SD sebagai bentuk penerapan literasi digital

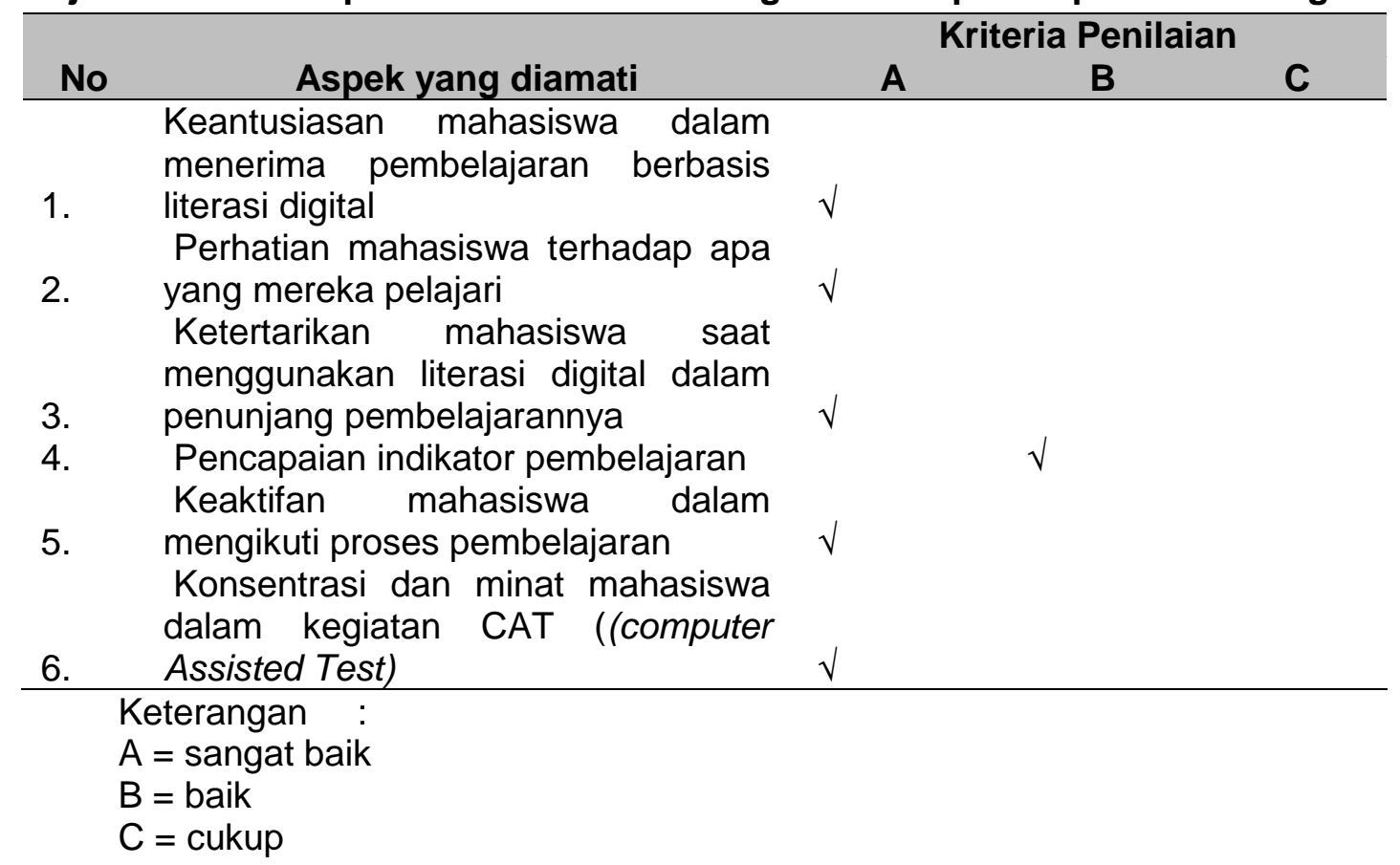

\section{B. Pembahasan}

1. Pembahasan Data Berdasarkan Hasil CAT (computer Assisted Test)

Dengan memperhatikan hasil tes hasil belajar pada matakuliah Pendidikan IPS SD mahasiswa PGSD menunjukkan bahwa nilai rata-rata yang diperoleh sebelum literasi digital pembelajaran yaitu dengan nilai 54,77. Maka hal ini ditunjukkan oleh adanya pada kriteria penialaian yaitu :

a. Sangat memuaskan ( 2 orang atau $7,40 \%$ ) dengan nilai $(85-100$ )

b. Memuaskan ( 5 orang atau 18,52\%) dengan nilai (70 -85)

c. Cukup memuaskan ( 5 orang atau $18,52 \%$ ) dengan nilai (55-60)

d. Kurang memuaskan (10 orang atau $37,04 \%$ ) dengan nilai $(40-55)$

e. Sangat tidak memuaskan ( 5 orang atau $18,52 \%$ ) dengan nilai $(0-35)$

Berdasarkan hasil tes awal, maka peneliti perlu untuk mengadakan perbaikan pembiasaaan literasi digital pada mahasiswa PGSD STKIP Bina Insan Mandiri mata kuliah Pendidikan IPS SD.

Berdasarkan data hasil yang kedua yaitu dengan menggunakan CAT (computer Assisted Test) diperoleh data rata-rata kelas adalah 72,81 . Hal ini menunjukkan adanya peningkatan terhadap penerapan budaya literasi digital 
dilingkungan program studi PGSD khususnya pembelajaran matakuliah Pendidikan IPS SD Hal ini sesuai dengan pernyataan Shymansky dalam suparno (1997) yang mengemukakan bahwa kegiatan belajar adalah kegiatan yang aktif dimana mahasiswa dapat membangun sendiri pengetahuannya, ini merupakan proses menyesuaikan konsep-konsep dan ide-ide baru dengan kerangka berfikir yang telah ada dalam pikiran mereka.

Untuk mengetahui peningkatan literasi digital siswa dalam kajian matakuliah pendidikan IPS SD yang lebih rinci, maka penulis akan menjelaskan sebagai berikut :

a. Mahasiswa yang mendapatkan kriteria sangat memuaskan dengan nilai 85100 pada tes awal sebelum menggunakan literasi digital sebanyak 2 orang mahasiswa dengan persentase $7,40 \%$. Hal ini menunjukkan peningkatan kemampuan literasi digital mahasiswa PGSD STKIP Bina Insan Mandiri sebanyak 3 orang dengan persentase $11,11 \%$.

b. mahasiswa yang mendapatkan kriteria memuaskan dengan nilai 70-85 pada tes awal sebelum literasi digital sebanyak 5 orang siswa dengan persentase 18,52 \%. Hal ini menunjukkan adanya peningkatan literasi digital mahasiswa PGSD STKIP Bina Insan Mandiri sebanyak 15 orang dengan persentase $55,55 \%$.

c. Mahasiswa yang mendapatkan kriteria cukup memuaskan dengan nilai 6065 pada tes awal sebelum literasi digital sebanyak 5 orang siswa dengan persentase 18,52 \% sedangkan pada tes akhir sesudah menggunakan literasi digital berkurang menjadi 3 orang dengan persentase $11,11 \%$. Hal ini disebabkan mahasiswa yang semula mendapatkan nilai 60-65 pada tes awal mampu meningkatkan nilainya sehingga mahasiswa yang mendapatkan nilai 60-65 berkurang jumlahnya.

d. Begitu juga dengan mahasiswa yang mendapat nilai 40-55 dengan kriteria kurang memuaskan pada tes awal sebanyak 10 orang mahasiswa dengan persentase $37,04 \%$, pada tes akhir berkurang menjadi 6 orang mahasiswa dengan persentase $22,22 \%$. Hal ini disebabkan mahasiswa yang semula mendapatkan nilai 40 - 55 pada tes awal mampu meningkatkan nilainya sehingga mahasiswa yang mendapat nilai 40-55 berkurang jumlahnya.

e. mahaiswa yang mendapat nilai 0-35 dengan kriteria sangat tidak memuaskan yang semula berjumlah 5 orang dengan persentase 18,52 \% menjadi tidak ada. Hal itu disebabkan mahasiswa yang mendapatkan nilai antara 0-35 mampu meningkatkan nilainya menjadi lebih baik.

\section{Pembahasan Data Hasil Observasi dalam Proses Pembelajaran}

Berdasarkan data observasi yang dilakukan peneliti pada proses pembelajaran berlangsung, dapat diperoleh data terhadap sikap atau tingkah laku mahasiswa dalam mengikuti kegiatan literasi digital matakuliah pendidikan IPSD SD. Untuk mengetahui sikap mahasiswa dalam literasi digital secara rinci dapat dijelaskan bahwa :

a. Keantusiasan mahasiswa dalam menerima pembelajaran berbasis literasi digital berada pada posisi sangat baik

b. Perhatian mahasiswa terhadap apa yang mereka pelajari berada pada posisi sangat baik

c. Ketertarikan mahasiswa saat menggunakan literasi digital dalam penunjang pembelajarannya berada pada posisi sangat baik

d. Pencapaian indikator pembelajaran pada posisi baik

e. Keaktifan mahasiswa dalam mengikuti proses pembelajaran berada pada posisi sangat baik 
f. Konsentrasi dan minat mahasiswa dalam kegiatan CAT ((computer Assisted Test) pada saat proses pembelajaran berlangsung berada pada posisi sangat baik.

Dari hasil penelitian yang telah dilakukan dan dengan melihat pembahasan di atas dapat diketahui adanya peningkatan dan keberhasilan dalam penerapan budaya literasi digital di lingkup Prodi PGSD STKIP Bina Insan Mandiri.

Hasil penelitian ini menunjukkan bahwa mahasiswa yang mampu melaksanakan literasi digital dan terbiasa dalam literasi hal ini telah terbukti dari data hasil tes dan hasil observasi yang diperoleh oleh peneliti.

\section{SIMPULAN}

Dari hasil penelitian yang telah dilakukan dan dengan melihat pembahasan di atas dapat disimpulkan adanya peningkatan dan keberhasilan dalam penerapan budaya literasi digital di lingkup Prodi PGSD STKIP Bina Insan Mandiri dengan aktivitas mahasiswa yang telah diobservasi selama proses kegiatan pembelajaran diwilayah kampus STKIP Bina Insan Mandiri . Berdasarkan data hasil yang kedua yaitu dengan menggunakan CAT (computer Assisted Test) diperoleh data rata-rata kelas adalah 72,81. Hal ini menunjukkan adanya peningkatan hasil belajar mahasiswa terhadap penerapan budaya literasi digital dilingkungan program studi PGSD khususnya pembelajaran matakuliah Pendidikan IPS SD.

\section{DAFTAR PUSTAKA}

Bawden, D. (2001). "Information and Digital Literacies: A Review of Concepts" http://www.Isisi.org/pakar-literasi-media-penting-untuk-masyarakat-digital/

Buletin Pos dan Telekomunikasi Vol. 14 No.2. 2016: 79-94. 